\title{
Efficacy of switching therapy to aflibercept for patients with persistent diabetic macular edema: a systematic review and meta-analysis
}

\author{
Yilin Liu ${ }^{1 \#}$, Jiahan Cheng ${ }^{2 \#}$, Yunxia Gao ${ }^{1}$, Ling Qin $^{1}$, Xiaoxue Min ${ }^{1}$, Ming Zhang ${ }^{1}$ \\ ${ }^{1}$ Department of Ophthalmology, ${ }^{2}$ Department of Thoracic Surgery, West China Hospital, Sichuan University, Chengdu 610041, China \\ Contributions: (I) Study conception and design: Y Liu; (II) Administrative support: M Zhang; (III) Provision of study materials or patients: Y Liu, J \\ Cheng; (IV) Collection and assembly of data: Y Liu, J Cheng; (V) Data analysis and interpretation: All authors; (VI) Manuscript writing: All authors; \\ (VII) Final approval of manuscript: All authors. \\ \#These authors contributed equally to this work. \\ Correspondence to: Ming Zhang. Department of Ophthalmology, West China Hospital, Sichuan University, No. 37, Guoxue Alley, Chengdu 610041, \\ China. Email: zhangmingscu@126.com.
}

Background: To evaluate functional and anatomical consequences of switching anti-vascular endothelial growth factor (anti-VEGF) therapy from bevacizumab and/or ranibizumab to aflibercept intravitreal injection for the treatment of persistent diabetic macular edema (DME).

Methods: Analysis of switching treatment in patients with persistent DME was performed using a literature search across multiple databases (PubMed, Medline, EMBASE, Cochrane Library and Web of Science) prior to May 2019. Therapeutic effect parameters, including mean change of best-corrected visual acuity (BCVA) and central macular thickness (CMT), were extracted from baseline to different follow-up times post initial injections. The quality of studies was assessed with the Downs and Black checklist. Data pertaining to ocular and systemic safety adverse events (SAEs) were collected as well as subgroup analysis stratified by preswitch anti-VEGF reagents. All results were analyzed and pooled using random-effects models with $95 \%$ confidence intervals (CI).

Results: Fourteen studies involving 489 eyes met the inclusion criteria. The mean differences in BCVA were significantly improved at 1,2 and 3 months with $-0.11 \log M A R(P=0.016),-0.22 \log \operatorname{MAR}(\mathrm{P}<0.001)$ and $-0.24 \log$ MAR $(\mathrm{P}<0.01)$, respectively. Vision gain was also assessed following the aflibercept injection with a mean change of $-0.10 \log$ MAR $(\mathrm{P}<0.001)$ at 6 months and $-0.08 \log$ MAR $(\mathrm{P}=0.01)$ at 12 months. CMT reduction was significant from baseline with a mean decrease of $80.52 \mu \mathrm{m}(\mathrm{P}<0.001)$ at 1 month, $89.6 \mu \mathrm{m}(\mathrm{P}<0.013)$ at 2 months, $113.88 \mu \mathrm{m}(\mathrm{P}<0.001)$ at 3 months and $125.12 \mu \mathrm{m}(\mathrm{P}<0.001)$ at 6 months. Mean CMT continued to decline by $75.70 \mu \mathrm{m}(\mathrm{P}<0.001)$ at 12 months as well.

Conclusions: This meta-analysis indicated the comparable efficacy and safety of a conversion treatment to aflibercept in cases of unsatisfactory responses to other anti-VEGF drugs. Switching treatment produces significant advantage for vision acuity recovery and macular edema improvement among persistent DME patients.

Keywords: Aflibercept; anti-vascular endothelial growth factor; diabetic macular edema (DME); switching treatment

Submitted Sep 14, 2019. Accepted for publication Jan 10, 2020.

doi: $10.21037 / \mathrm{atm} .2020 .02 .04$

View this article at: http://dx.doi.org/10.21037/atm.2020.02.04 


\section{Introduction}

Diabetic macular edema (DME), a sight-threatening complication of diabetic retinopathy (DR), is clinically characterized by retinal thickening of extracellular fluid exudation and accumulation in the macula area secondary to abnormal vascular permeability (1). Global prevalence of DME is $6.81 \%$ and the number of DME patients was approximately 20.6 million in 2010 (2).

Vascular endothelial growth factor (VEGF) has been demonstrated to be a pivotal mediator that contributes to the pathogenesis of DME $(3,4)$. In recent years, antivascular endothelial growth factor (anti-VEGF) drugs have become first-line treatment for DME, showing beneficial vision gain and control of disease progression (5). However, some patients failed a response to intravitreal bevacizumab (IVB) or ranibizumab (IVR) after a minimum of three injections treatment (6-8) and may develop persistent fluid re-accumulation and neuronal damage within the retina, leading to visual impairment and limited vision recovery (9).

It is suggested that a conversion treatment to a latest anti-VEGF drug, aflibercept, could improve chronic macular edema and provide long-term vision benefits. Compared to bevacizumab and ranibizumab, aflibercept substantially has multiple targets, higher binding affinity to VEGF-A and additionally inhibits placental growth factor and VEGF-B (10).

Several clinical trials have suggested that DME patients with incomplete response to previous anti-VEGF injections may benefit from an alternative anti-VEGF therapy, showing superiority of aflibercept over bevacizumab or ranibizumab (11-13). Pharmacologic conversion represents a promising strategy for treating resistant DME, yet the efficacy of this treatment has not been evaluated comprehensively.

To address this gap in knowledge, we performed a systematic meta-analysis to investigate the outcomes of visual and retinal anatomical changes among DME refractory patients following conversion to aflibercept therapy.

\section{Methods}

\section{Literature search}

A computational search was performed to collect relevant studies across five databases (PubMed, Medline, EMBASE, Cochrane Library and Web of Science) prior to May 30. The search strategy was carried out using the Medical Subject Headings and keywords "diabetic macular edema or DME" with "aflibercept", as well as any of the following words: "resistant", "refractory", "recalcitrant", "conversion", "switching" and "non-response". Studies published in English reporting a switch from one anti-VEGF drug (bevacizumab or ranibizumab) to aflibercept in longstanding DME were collected and all date ranges available in the databases were included.

\section{Eligibility criteria}

Clinical trials that met the following criteria were deemed eligible: (I) patients over 18 years of age with persistent DME who had switched to aflibercept from previous unresponsive anti-VEGF therapy (bevacizumab or/and ranibizumab); (II) studies that provided both main outcome evaluation parameters as mean $\pm \mathrm{SD}$ : best-corrected visual acuity (BCVA) and central macular thickness (CMT); (III) all randomized controlled trials (RCTs), cohort studies, and retrospective studies with full-text articles; (IV) all included studies should be compliant with the Declaration of Helsinki and written informed consent from enrolled patients. Conference abstract, letters without data, reviews and case reports with fewer than five cases were excluded. If the same study subjects were reported in different publications, only the most recent publication was included.

\section{Data extraction and quality assessment}

Assessment of full-text articles and data extraction from each study was independently conducted by two authors (YL and $\mathrm{JH}$ ), including publication metrics (name of the first author, year of publication, location and study design), demographic characteristics (number of eyes and mean age), treatment information (pre-switch and post-switch injection numbers, type of anti-VEGF drug, injection intervals), duration of follow-up and treatment outcomes corresponding to BCVA and CMT. If studies have missing data in terms of mean and standard deviation (SD) in BCVA and CMT parameters but provided each patient's original vision and CMT records, we primarily calculated the mean and SD data and then acquired the paired difference based on The Cochrane Handbook (14) of the following formula:

$\mathrm{SD}$ paireddifference $={ }^{\vee}\left[\left(\mathrm{SD}_{1}\right)^{2}+\left(\mathrm{SD}_{2}\right)^{2}-2 \times \mathrm{r} \times \mathrm{SD}_{1} \times \mathrm{SD}_{2}\right]$.

$\mathrm{SD}_{1}=$ standard deviation of the pre-treatment value, $\mathrm{SD}_{2}=$ standard deviation of the post-treatment value, $\mathrm{r}=$ correlation coefficient. We set $\mathrm{r}=0.4$ as correlation coefficient.

The methodological quality assessment of selected 
studies was measured using criteria from a modified version of the Downs and Black checklist (15) independently by two independent reviewers. The tool is appropriate for both randomized and non-randomized studies with total scores ranging from 0 to 28. Consequently, higher scores indicated lower risk of bias and studies scored less than 15 were excluded in this meta-analysis. To aid in interpretation of different scores, we classified study quality and risk of bias as follows: poor quality [0-14], high risk of bias; fair quality [15-19], moderate risk of bias and high quality [20-28], low risk of bias. All studies were assessed as fair quality, moderate risk of bias. Any conflicting evaluations or disparities were resolved through discussion and consensus.

\section{Evaluation indicators}

Vision-related outcomes of treatment efficacy included mean changes in BCVA and CMT, from pre-switch baseline to different post-switch endpoints. When BCVA data was presented in Early Treatment Diabetic Retinopathy Study (ETDRS) letter scores or Snellen acuity fraction, it was transposed to logarithm of the minimum angle of resolution (log MAR) units (15). Safety indicators included systemic or ocular safety adverse events during the injection treatment.

\section{Statistical analysis}

We analyzed the quantitative evidence with STATA version 12.0 (STATA corporation, college station, TX). Continuous data were expressed as means and standard deviations, and weighted mean differences (WMD) were calculated. Besides, they were recorded as mean differences with corresponding $95 \%$ confidence intervals (CIs). Heterogeneity variances were estimated by means of a standard $\chi^{2}$-based Cochran's $Q$ test along with the $\mathrm{I}^{2}$ statistic, measuring the percentage of variability that cannot be attributed to random error. $\mathrm{P}<0.1$ and $\mathrm{I}^{2} \geq 50 \%$ indicates a considerable level of heterogeneity. Randomeffect models were used to pool the data since the interventions varied among included studies (16). Potential publication bias was assessed by Begg's and Egger's test and funnel plots with $\mathrm{P}>0.05$ indicating negative publication bias. One-way sensitivity analysis was performed to detect the stability of outcomes using the leave-one out approach. Statistical significance was determined using the twotailed test, where $\mathrm{P}$ values less than 0.05 were defined as significant.

\section{Results}

\section{Description of studies}

A total of 38 studies were initially identified by the search terms prior to May 2019, of which 13 studies were excluded as reviews or letters and 6 studies were removed manually after skimming through the titles or abstracts. Additionally, two articles reported the same trial at different time points, so we kept the most recent one. Among the remaining 19 trials, 5 articles were rejected due to the eligibility criteria. Of the 14 studies, there were 5 prospective studies and 9 retrospective studies finally included for meta-analysis (Table 1), and all available studies met the eligibility standards described above. The literature selection process and reasons for exclusion are summarized in (Figure 1).

\section{Baseline characteristics}

Basic information and quality assessment scores for the 14 studies are listed in Table 1 and Table S1. Overall, sample sizes varied from 11 to 72 eyes, with a total of 489 eyes included in the analyses and the duration of follow-up time ranged from 1 to 24 months. Mean age and HbA1c levels of all the patients ranged from 56.07 to 70.3 years old and $6.9 \%$ to $8.0 \%$, respectively. The mean baseline BCVA logMAR scores ranged from 0.33 to 0.87 and mean CMT ranged from 324.0 to $501.47 \mu \mathrm{m}$. Eyes received a mean number of anti-VEGF injections pre-switch ranged from 4.3 to 21.1. Injection numbers differed in the post-switch aflibercept treatment, but most trials used pro re nata (PRN) dosing after 3 monthly regular doses.

\section{Best-corrected visual acuity}

BCVA data was selected as an essential visual outcome parameter to evaluate the switch treatment efficacy. The mean change in BCVA of each study was assessed from baseline to several post-switch endpoints using forest plots. Six studies, with a total of 216 , eyes were included in comparison of BCVA changes from baseline to the first month after conversion therapy. The pooled results revealed a visual acuity improvement in BCVA from baseline with a mean increase of $-0.11 \log$ MAR (95\% CI, -0.20 to -0.02 logMAR, $\mathrm{P}=0.016$; Figure $2 A$ ). In the three studies ( $\mathrm{n}=80$ eyes) with 2 months of follow-up, significant changes can be confirmed in the evaluation of BCVA from baseline with a mean increase of $-0.22 \log \mathrm{MAR}$ (95\% CI, -0.32 to $-0.12 \log \mathrm{MAR}, \mathrm{P}<0.001$; Figure $2 \mathrm{~B}$ ). BCVA improvement 


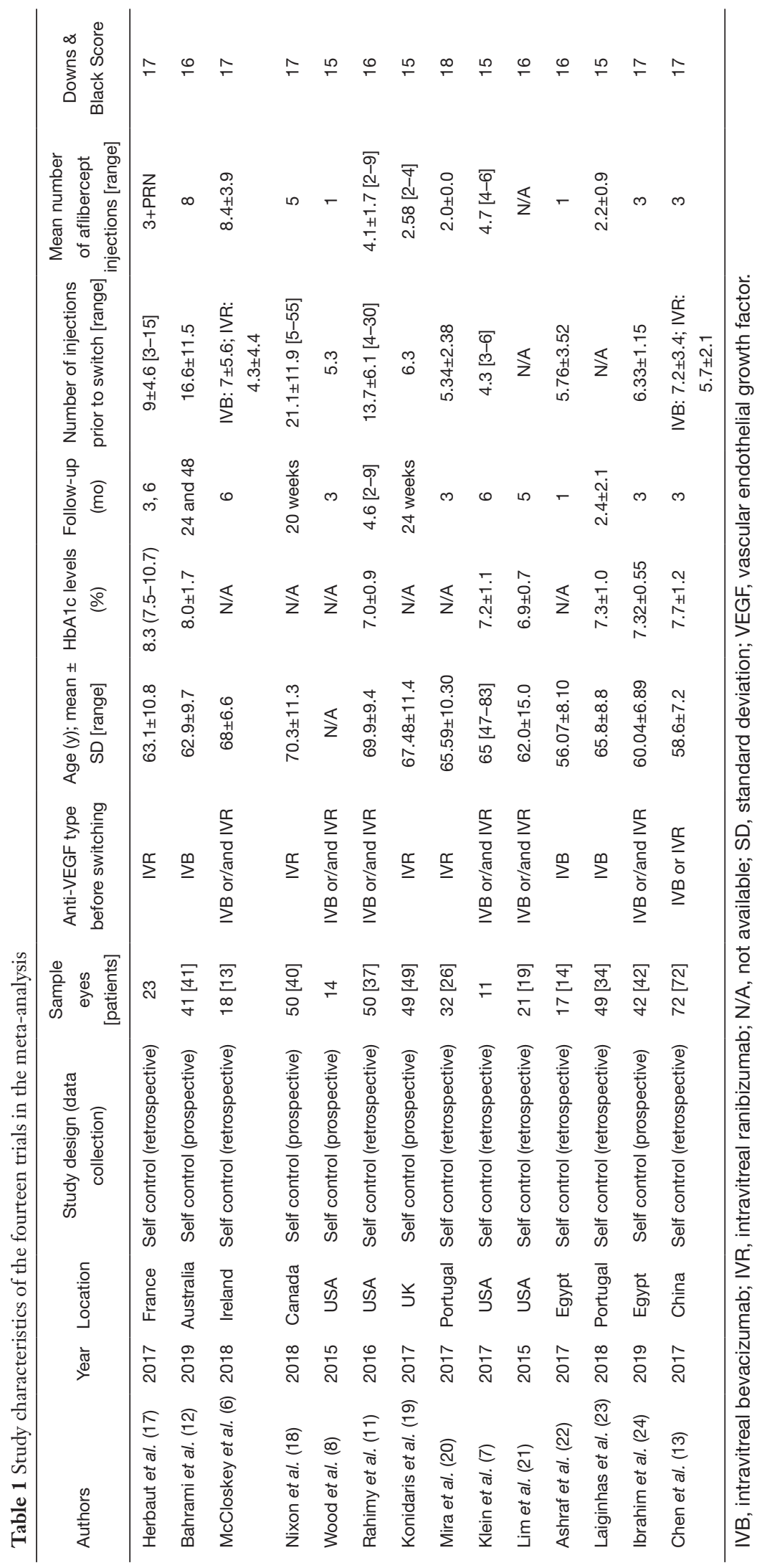



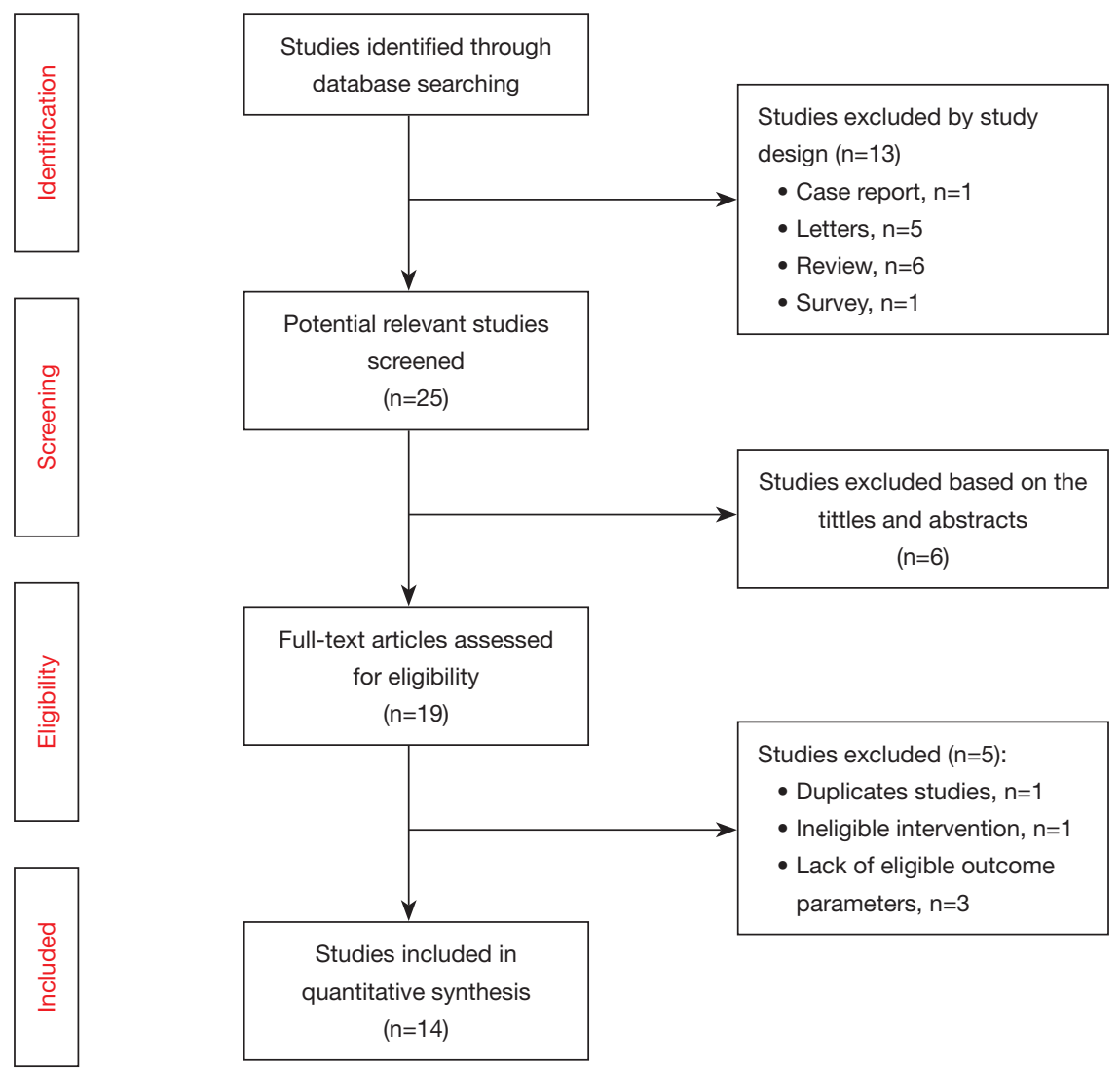

Figure 1 PRISMA flow diagram of study identification process.

was analyzed in five studies from baseline to 3 months after aflibercept injection. The pool mean improvement was $-0.24 \log$ MAR $(95 \%$ CI, -0.42 to $-0.06 \log M A R, P<0.01$; Figure 2C) for 219 eyes. However, the results indicated a significant difference in BCVA post-aflibercept switch at 5 months follow-up between two studies, while results fluctuated when we analyzed the data with a mean change of $-0.05 \log$ MAR (95\% CI, -0.10 to $-0.00 \log$ MAR, $\mathrm{P}=0.052$ ). At 6 and 12 months, BCVA significantly improved by a mean of $-0.10 \log$ MAR $(\mathrm{n}=142,95 \% \mathrm{CI},-0.14$ to -0.05 $\log \mathrm{MAR}, \mathrm{P}<0.001$; Figure $2 \mathrm{D})$ and $-0.08 \log \mathrm{MAR}(\mathrm{n}=59$, $95 \%$ CI, -0.13 to $-0.02 \log$ MAR, $\mathrm{P}=0.01$; Figure $2 E$ ), respectively. There was no significant heterogeneity found among the 5 studies at 6 months $\left(\mathrm{I}^{2}=0 \%, \mathrm{P}=0.54\right)$. Likewise, no statistical evidence indicated heterogeneity between 2 studies at the 12 -month time point $\left(\mathrm{I}^{2}=8.2 \%, \mathrm{P}=0.30\right)$.

\section{Central macular thickness}

The progress of anatomical outcome of each study from baseline to different follow-up time is shown in Figure 3.
One month following the switch of anti-VEGF, CMT of 216 patients in six studies declined with a mean of $80.52 \mu \mathrm{m}$ (95\% CI, -109.34 to $-51.70 \mu \mathrm{m}, \mathrm{P}<0.001$; Figure $3 A$ ). Three studies were included in the assessment of CMT between baseline and 2 months, with a mean reduction of $89.6 \mu \mathrm{m}(95 \% \mathrm{CI},-160.41$ to $-18.78 \mu \mathrm{m}, \mathrm{P}<0.013$; Figure $3 B)$. Reduction of CMT was reported at 3-month time point in five studies, demonstrating a mean decrease of $113.88 \mu \mathrm{m}$ (95\% CI, -156.72 to $-71.04 \mu \mathrm{m}, \mathrm{P}<0.001$; Figure 3 C). Results from two studies indicated a significant difference at 5 months whereas the results fluctuated through the analysis (95\% CI, -170.22 to $14.01 \mu \mathrm{m}, \mathrm{P}=0.09)$. Six studies at month 6 and 12 studies at month 12 were analyzed in the assessment of CMT outcomes as well, which reduced with a mean of $125.12 \mu \mathrm{m}$ (95\% CI, -185.32 to $-64.92 \mu \mathrm{m}$, $\mathrm{P}<0.001$; Figure $3 D)$ and $75.70 \mu \mathrm{m}(95 \% \mathrm{CI},-114.92$ to $-36.48 \mu \mathrm{m}, \mathrm{P}<0.001$; Figure 3 E), respectively.

\section{Subgroup analysis}

Classification of different anti-VEGFs (IVB, IVR, IVB or/ 


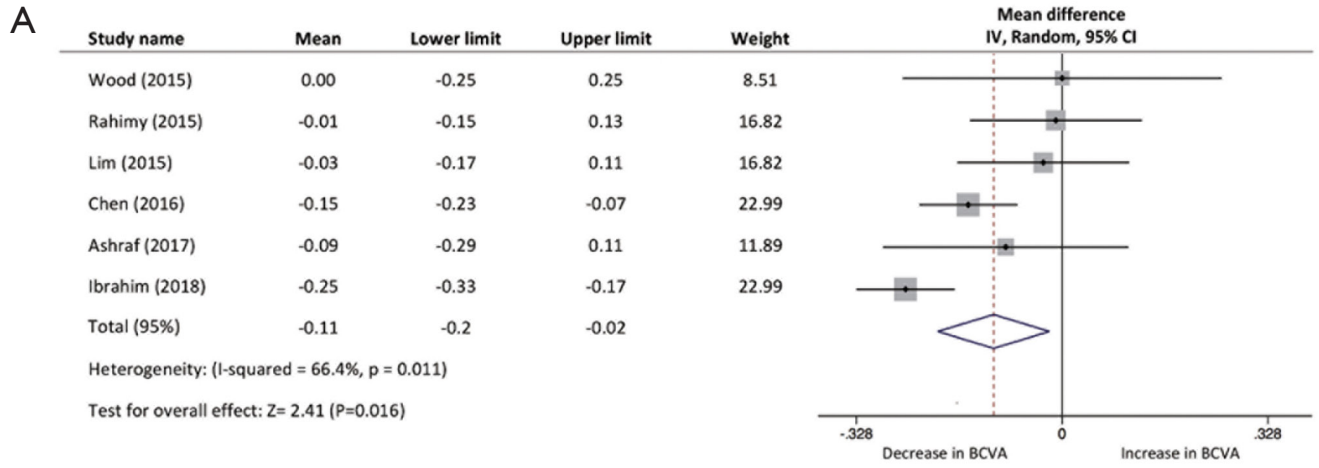

B

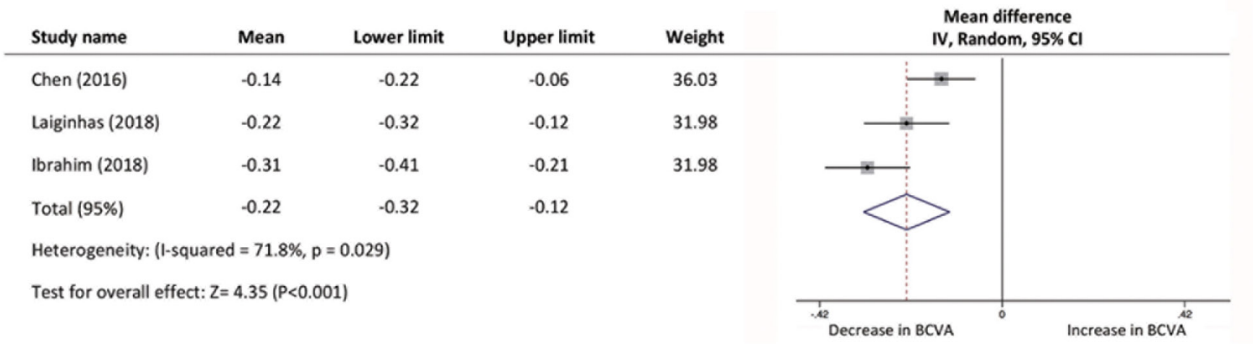

C

\begin{tabular}{|c|c|c|c|c|c|}
\hline Study name & Mean & Lower limit & Upper limit & Weight & $\begin{array}{l}\text { Mean difference } \\
\text { IV, Random, } 95 \% \mathrm{C}\end{array}$ \\
\hline
\end{tabular}

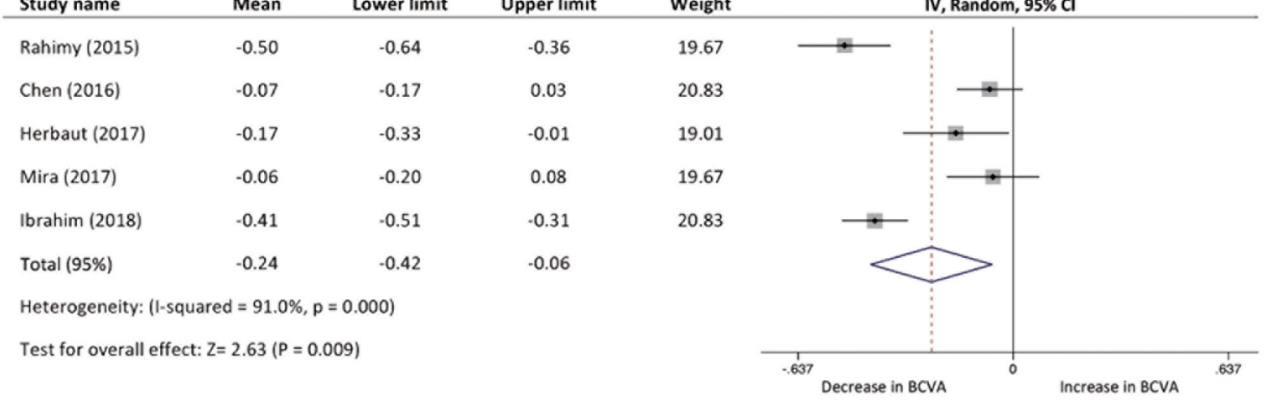

D

\begin{tabular}{lcccc} 
Study name & Mean & Lower limit & Upper limit & Wei \\
\hline Herbaut (2017) & -0.16 & -0.32 & 0.00 & 6.8 \\
Konidaris (2017) & -0.13 & -0.21 & -0.05 & 27.53 \\
Klein (2017) & -0.15 & -0.35 & 0.05 & 4.41 \\
McCloskey (2018) & -0.10 & -0.22 & 0.02 & 12.24 \\
Bahrami (2019) & -0.06 & -0.12 & 0.00 & 48.94
\end{tabular}

Total (95\%) $\quad-0.10 \quad-0.14 \quad-0.05$

Heterogeneity: (1-squared $=0.0 \%, p=0.542$ )

Test for overall effect: $Z=4.53(p<0.001)$

E

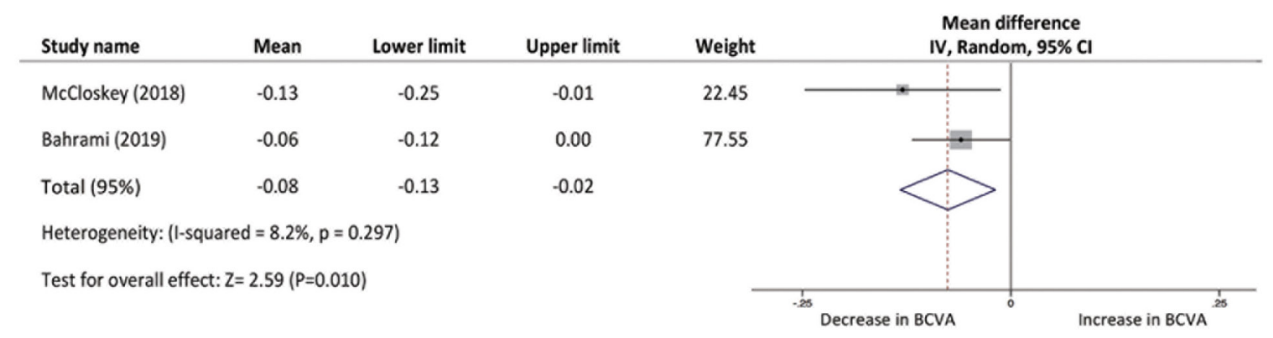

Figure 2 Forest plot of each study with mean change of best-corrected visual acuity (BCVA, $\log$ MAR) from baseline to different follow-up times after switching to aflibercept. (A) 1 month; (B) 2 months; (C) 3 months; (D) 6 months; (E) 12 months. 
A

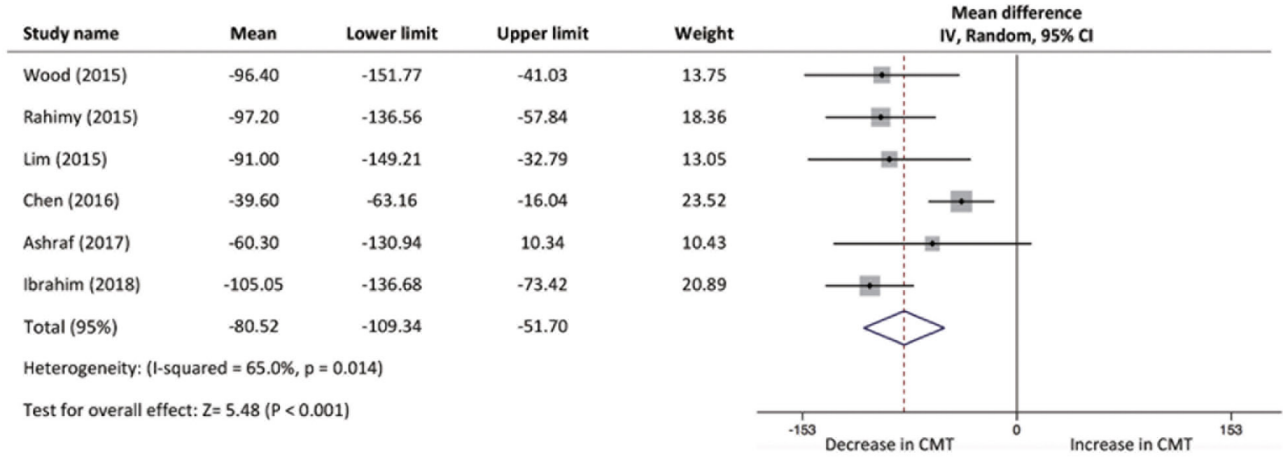

B

\begin{tabular}{lcccc|c} 
Study name & Mean & Lower limit & Upper limit & Weight & \multicolumn{2}{c}{$\begin{array}{c}\text { Mean difference } \\
\text { IV, Random, 95\% Cl }\end{array}$} \\
\hline Chen (2016) & -24.00 & -49.89 & 1.89 & 34.18 \\
Laiginhas (2018) & -124.00 & -162.20 & -85.80 & 32.44 \\
Ibrahim (2018) & -123.33 & -155.30 & -91.36 & 33.38 \\
Total (95\%) & -89.60 & -160.41 & -18.78 & & \\
Heterogeneity: (I-squared $=93.3 \%, \mathrm{p}<0.001)$ & & & Decrease in CMT \\
Test for overall effect: $Z=2.48(\mathrm{P}=0.013)$ &
\end{tabular}

C

\begin{tabular}{lcccc} 
Study name & Mean & Lower limit & Upper limit & Weight \\
\hline Rahimy (2015) & -110.50 & -148.70 & -72.30 & 20.63 \\
Chen (2016) & -41.40 & -74.68 & -8.12 & 21.48 \\
Herbaut (2017) & -155.20 & -206.24 & -104.16 & 18.28 \\
Mira (2017) & -133.50 & -186.03 & -80.97 & 18.00 \\
Ibrahim (2018) & -137.86 & -170.38 & -105.34 & 21.6 \\
Total (95\%) & -113.88 & -156.72 & -71.04 &
\end{tabular}

Heterogeneity: (1-squared $=82.5 \%, p<0.001)$

Test for overall effect: $Z=5.21(P<0.001)$

D

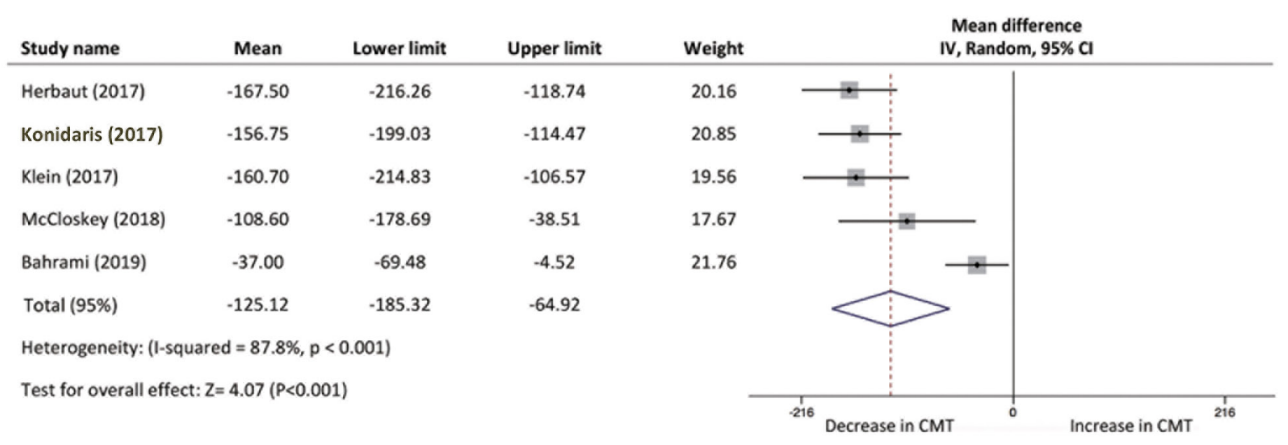

E

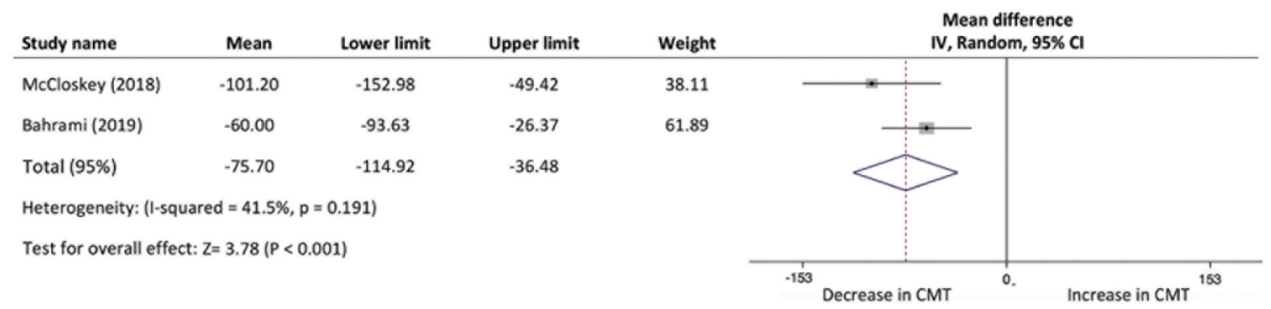

Figure 3 Forest plot of each study with mean change of central macular thickness (CMT, $\mu \mathrm{m})$ from baseline to different follow-up times after switching to aflibercept. (A) 1 month; (B) 2 months; (C) 3 months; (D) 6 months; (E) 12 months. 
Table 2 Subgroup analysis of BCVA and CMT outcomes according to pre-switch reagents (mean and 95\% confidence intervals)

\begin{tabular}{lccc}
\hline & IVR & IVB & IVR and/or IVB \\
\hline BCVA 1 month (logMAR) & N/A & $-0.09(-0.29$ to -0.11$)$ & $-0.11(-0.21$ to -0.01$)$ \\
BCVA 3 month (logMAR) & $-0.11(-0.22$ to -0.00$)$ & N/A & $-0.32(-0.58$ to -0.06$)$ \\
BCVA 6 month (logMAR) & $-0.14(-0.21$ to -0.07$)$ & $-0.06(-0.12$ to -0.00$)$ & $-0.11(-0.21$ to -0.01$)$ \\
CMT 1 month $(\mu \mathrm{m})$ & N/A & $-60.30(-130.94$ to 10.34) & $-83.24(-115.57$ to -50.92$)$ \\
CMT 3 month $(\mu \mathrm{m})$ & $-144.66(-181.27$ to -108.06$)$ & N/A & $-96.50(-155.15$ to -37.85$)$ \\
CMT 6 month $(\mu \mathrm{m})$ & $-161.36(-193.31$ to -129.42$)$ & $-37.00(-69.48$ to -4.52$)$ & $-139.60(-189.73$ to -89.47$)$ \\
\hline
\end{tabular}

BCVA, best-corrected visual acuity; CMT, central macular thickness; IVB, intravitreal bevacizumab; IVR, intravitreal ranibizumab; logMAR, logarithm of the minimum angle of resolution; N/A, not available.

and IVR) before the switching treatment was subjected to subgroup analysis. Due to the limitation of study number, only three follow-up time points were included (Table 2). BCVA changes between IVB or/and IVR subgroup and IVB subgroup were comparable. The former subgroup demonstrated a greater visual improvement, while IVB subgroup was observed no significant gain at 1 month $(-0.09 \log$ MAR, $95 \%$ CI, -0.29 to $-0.11 \log \mathrm{MAR}, \mathrm{P}=0.368$; Figure 51$)$ and a slight mean change at 6 months $(-0.06 \log M A R$, $95 \%$ CI, -0.12 to $-0.00 \log$ MAR, $\mathrm{P}=0.046$; Figure 1 ), respectively.

The mean reduction of CMT in pre-switch IVR treatment subgroup was measured at 3 months $(144.66 \mu \mathrm{m}$, $95 \% \mathrm{CI},-181.27$ to $-108.06 \mu \mathrm{m}, \mathrm{P}<0.001$; Figure $S 2)$ and 6 months $(161.36 \mu \mathrm{m}, 95 \% \mathrm{CI},-193.31$ to $-129.42 \mu \mathrm{m}$, $\mathrm{P}<0.001$; Figure $S 2)$, greater than other two subgroups. Moreover, the pool results revealed a better mean CMT decrease in IVR or/and IVB group at 1 month $(83.24 \mu \mathrm{m}$, 95\% CI: -115.57 to $-50.92 \mu \mathrm{m}, \mathrm{P}<0.001$; Figure S2) and 6 months $(139.60 \mu \mathrm{m}, 95 \% \mathrm{CI}:-189.73$ to $-89.47 \mu \mathrm{m}$, $\mathrm{P}<0.001$; Figure 52$)$ when compared to IVB group $(60.30 \mu \mathrm{m}, 95 \% \mathrm{CI}:-130.94$ to $10.34 \mu \mathrm{m}, \mathrm{P}=0.094$; Figure S2) and $(37.00 \mu \mathrm{m}, 95 \% \mathrm{CI}:-69.48$ to $-4.52 \mu \mathrm{m}$, $\mathrm{P}=0.026$; Figure S2), respectively.

\section{Publication bias}

All studies were deemed to exhibit no publication bias when analyzed from visual inspection of the funnel plots and by Begg's test $(\mathrm{P}=0.343 \mathrm{BCVA}$ and $\mathrm{P}=0.546 \mathrm{CMT})$, but possible bias evidence was tested by Egger's test $(\mathrm{P}=0.343$ BCVA and $\mathrm{P}=0.031 \mathrm{CMT}$ ). Strong evidence of possible inter-study heterogeneity was observed in the overall pooling of all eligible studies in both BCVA $\left(\mathrm{I}^{2}=84.1 \%\right.$,
$\mathrm{P}<0.001)$ and CMT.

\section{Safety}

Instances of safety adverse events (SAEs) were few among all studies and no significant heterogeneity was tested. Of the 14 trials, 9 studies reported no severe SAEs and 4 studies showed no safety data during the treatment. Despite some typical side effects associated with intravitreal injections, such as subconjunctival hemorrhage, severe ocular SAEs were minimal with only 1 study recording a patient with rhegmatogenous retinal detachment. Twelve significant systemic SAEs (myocardial infraction, etc.) were reported in one study during the follow-up period (12). Whether these events are drug-related issues remains unclear.

\section{Discussion}

Diabetic macular edema is reportedly the most common manifestation of DR, which can cause vision impairment in patients with diabetes. Notably, injections of anti-VEGF reagents have become the standard treatment worldwide in DME patients (25).

However, DME chronically persists in a portion of patients, who somehow suffered from suboptimal or worsening responses to bevacizumab or ranibizumab. Lack of response to these therapies can be attributed to the phenomenon known as tachyphylaxis or tolerance $(26,27)$. Preliminary studies suggested a decreased bioefficacy in AMD patients after repeated IVB (28).

To address these patients, a novel therapeutic option, switching to aflibercept, has been used in limited trials, demonstrating potential benefit among patients with unsatisfactory responses to initial anti-VEGF drugs. One 
study (29) reported 10 patients with polypoidal choroidal vasculopathy (PCV) who developed tachyphylaxis to ranibizumab injections and suggested that the switching treatment was effective. Nevertheless, whether there was promising improvement after aflibercept injection or the feasibility of the conversion method in DME patients, needed to be assessed.

To the best of our knowledge, this is the first metaanalysis study that assessed the efficacy and safety of aflibercept retreatment in DME patients with other antiVEGF treatment failure.

In this meta-analysis, we examined 14 studies representing 489 eyes based on robust search method and precisely data extraction following a systematic review process. Based on the studies enrolled in this meta-analysis, most of the articles reported significant changes in BCVA and CMT parameters, which is in consistent with our overall results. Our analysis showed that DME patients could obtain significant visual improvement in BCVA as well as the anatomic reduction of CMT at 1, 2, 3, 6 and 12 months. Due to the limited data, it was impossible to evaluate treatment efficacy at longer time points.

The increased response in recalcitrant DME patients might reflect the particular pharmacologic profile of aflibercept. Among anti-VEGF drugs, only aflibercept can inhibit both placental growth factor (PGF) and VEGF, which are key factors contributing to the pathogenesis of DR or DME. More importantly, aflibercept is featured with faster association rate (77- and 256-fold faster than bevacizumab and ranibizumab, respectively) and higher binding affinity (about 100-fold higher) over other reagents yielding a doubling of VEGF blockade time (30). And then after the injection of active aflibercept fusion protein followed by new interaction with multiple inflammatory targets, the recurrent edema in a number of DME patients may be optimized due to the theoretical advantages of aflibercept.

Of note, patients in three studies $(8,11,31)$ were observed without significant gains in visual outcomes at the first month follow-up. One possible explanation is that those patients may require a longer-term regimen to reach a favorable effect. Since macular edema has caused persisting retinal damage, sustained treatment might be required for significant results. Another reason can be explained by the multifactorial etiology of DME. Anti-VEGF drugs are not functional for every inflammatory mediator involved in the pathological process, so other therapies or combination treatments need to be evaluated or discovered.
Subgroup analysis by different anti-VEGF agents administered pre-switch was conducted and the outcomes appeared to show different response rates between switching drugs. In contrast, patients who were given bevacizumab and/or ranibizumab treatment before were trended to obtain a better visual acuity and edema reduction than those with only bevacizumab injections. Additionally, non-responders with only ranibizumab injections presented greater morphological parameters than other two groups.

This meta-analysis contains some limitations. First of all, publication bias could not be excluded, which can be tested in the appraisal of both BCVA and CMT outcomes. The indication of the inter-study heterogeneity can be attributed to study designs and small cohort sizes. Moreover, only a limited number of published studies were available in this meta-analysis and no RCTs were included; the nature of nonrandomized trials may confound variables. Additionally, some studies have relatively small sample sizes (fewer than 20 patients) and thus may overvalue the efficacy of the switching therapy.

\section{Conclusions}

In short, our results presented positive evidence for conversion to aflibercept treatment in patients with DME resistance to either bevacizumab or ranibizumab. Even if this alternative strategy showed advantages in visual acuity and retina morphological changes at 1 month and 3 months follow-up time, more long-term data is needed to improve the accuracy of this meta-analysis, and provide guidance to clinicians.

\section{Acknowledgments}

The authors sincerely appreciate the efforts from Nathan E. Reticker-Flynn (postdoctoral scholar, Stanford University) for the English editing and revising of our study.

Funding: None.

\section{Footnote}

Conflicts of Interest: The authors have no conflicts of interest to declare.

Etbical Statement: The authors are accountable for all aspects of the work in ensuring that questions related to the accuracy or integrity of any part of the work are 
appropriately investigated and resolved.

Open Access Statement: This is an Open Access article distributed in accordance with the Creative Commons Attribution-NonCommercial-NoDerivs 4.0 International License (CC BY-NC-ND 4.0), which permits the noncommercial replication and distribution of the article with the strict proviso that no changes or edits are made and the original work is properly cited (including links to both the formal publication through the relevant DOI and the license). See: https://creativecommons.org/licenses/by-nc-nd/4.0/.

\section{References}

1. Ciulla TA, Amador AG, Zinman B. Diabetic retinopathy and diabetic macular edema: pathophysiology, screening, and novel therapies. Diabetes Care 2003;26:2653-64.

2. Yau JW, Rogers SL, Kawasaki R, et al. Global prevalence and major risk factors of diabetic retinopathy. Diabetes Care 2012;35:556-64.

3. Aiello LP, Avery RL, Arrigg PG, et al. Vascular endothelial growth factor in ocular fluid of patients with diabetic retinopathy and other retinal disorders. $\mathrm{N}$ Engl J Med 1994;331:1480-7.

4. Antonetti DA, Barber AJ, Hollinger LA, et al Vascular endothelial growth factor induces rapid phosphorylation of tigh junction proteins occluding and zonula occluden 1. A potential mechanism for vascular permeability in diabetic retinopathy and tumors. J Biol Chem 1999;274:23463-7.

5. Banaee T, Ashraf M, Conti FF, et al. Switching AntiVEGF Drugs in the Treatment of Diabetic Macular Edema. Ophthalmic Surg Lasers Imaging Retina 2017;48:748-54.

6. McCloskey CF, Mongan AM, Chetty S, et al. Aflibercept in Diabetic Macular Oedema Previously Refractory to Stanard Intravitreal Therapy: An Irish Retrospective Study. Ophthalmol Ther 2018;7:173-83.

7. Klein KA, Cleary TS, Reichel E. Effect of intravitreal aflibercept on recalcitrant diabetic macular edema. Int J Retina Vitreous 2017;3:16.

8. Wood EH, Karth PA, Moshfeghi DM, et al. Short-term outcomes of aflibercept therapy for diabetic macular edema in patients with incomplete response to ranibizumab and/ or bevacizumab. Ophthalmic Surg Lasers Imaging Retina 2015;46:950-4.

9. Nguyen QD, Tatlipinar S, Shah SM, et al. Vascular endothelial growth factor is a critical stimulus for diabetic macular edema. Am J Ophthalmol 2006;142:961-9.
10. Papadopoulos N, Martin J, Ruan Q, et al. Binding and neutralization of vascular endothelial growth factor (VEGF) and related ligands by VEGF Trap, ranibizumab and bevacizumab. Angiogenesis 2012;15:171-85.

11. Rahimy E, Shahlaee A, Khan MA, et al. Conversion to aflibercept after prior anti-VEGF therapy for persistent diabetic macular edema. Am J Ophthalmol 2016;164:118-27.e2.

12. Bahrami B, Hong T, Schlub TE, et al. Aflibercept for persistent diabetic macular edema: forty-eight-week outcomes. Retina 2019;39:61-8.

13. Chen YY, Chang PY, Wang JK. Intravitreal aflibercept for patients with diabetic macular edema refractory to bevacizumab or ranibizumab: analysis of response to aflibercept. Asia Pac J Ophthalmol (Phila) 2017;6:250-5.

14. Higgins JPT, Green S. Cochrance Handbook for Systematic Reviews of Interventions Version 5.1. The Cochrane Collaboration. Available online: http://www. cochrane-handbook.org

15. Downs SH, Black N. The feasibility of creating a checklist for the assessment of the methodological quality both of randomized and non-randomized studies of health care interventions. J Epidemiol Community Health 1998;52:377-84.

16. Gregori NZ, Feuer W, Rosenfeld PJ. Novel method for analyzing snellen visual acuity measurements. Retina 2010;30:1046-50.

17. Herbaut A, Fajnkuchen F, Qu-Knafo L, et al. Switching to Aflibercept in Diabetic Macular Edema Not Responding to Ranibizumab and/or Intravitreal Dexamethasone Implant. J Ophthalmol 2017;2017:8035013.

18. Nixon DR, Flinn NA. Evaluation of contrast sensitivity and other visual function outcomes in diabetic macular edema patients following treatment switch to aflibercept from ranibizumab. Clin Ophthalmol 2018;12:191-7.

19. Konidaris VE, Tsaousis KT, Al-Hubeshy Z, et al. Clinical real-world results of switching treatment from ranibizumab to aflibercept in patients with diabetic macular oedema. Eye 2017;31:1629-30.

20. Mira F, Paulo M, Henriques F, et al. Switch to Aflibercept in Diabetic Macular Edema Patients Unresponsive to Previous Anti-VEGF Therapy. J Ophthalmol 2017;2017:5632634.

21. Lim LS, Ng WY, Mathur R, et al. Conversion to aflibercept for diabetic macular edema unresponsive to ranibizumab or bevacizumab. Clin Ophthalmol 2015;9:1715-8.

22. Ashraf M, Souka AA, ElKayal H. Short-Term Effects 
of Early Switching to Ranibizumab or Aflibercept in Diabetic Macular Edema Cases With Non-Response to Bevacizumab. Ophthalmic Surg Lasers Imaging Retina 2017;48:230-6.

23. Laiginhas R, Silva MI, Falcao MS. Aflibercept in diabetic macular edema refractory to previous bevacizumab: outcomes and predictors of success. Graefes Arch Clin Exp Ophthalmol 2018;256:1355-6.

24. Ibrahim WS, Eldaly ZH, Saleh MG, et al. Switching to Aflibercept in Diabetic Macular Edema after Unsatisfactory Response to Other Anti-vascular Endothelial Growth Factor Drugs. Korean J Ophthalmol 2019;33:122-30.

25. Riley RD, Higgins JP, Deeks JJ. Interpretation of random effects meta-analyses. BMJ 2011;342:d549.

26. Namba R, Kaneko H, Suzumura A, et al. In Vitro Epiretinal Membrane Model and Antibody Permeability/Relationship With Anti-VEGF Resistance in Diabetic Macular Edema. Invest Ophthalmol Vis Sci
2019;60:2942-9.

27. Binder S. Loss of reactivity in intravitreal anti-VEGF therapy: Tachyphylaxis or tolerance. Br J Ophthalmol 2012;96:1-2.

28. Gokce G, Durukan AH, Koylu MT, et al. Efficacy of aflibercept on exudative age-related macular degeneration in patients exhibiting complete ranibizumab resistance and tachyphylaxis. Arq Bras Oftalmol 2016;79:384-9.

29. Schaal S, Kaplan HJ, Tezel TH. Is there tachyphylaxis to intravitreal anti-vascular endothelial growth factor pharmacotherapy in age-related macular degeneration. Ophthalmology 2008;115:2199-205.

30. Miura M, Iwasaki T, Goto H. Intravitreal aflibercept for polypoidal choroidal vasculopathy after developing ranibizumab tachyphylaxis. Clin Ophthalmol 2013;7:1591-5.

31. Avitabile T, Azzolini C, Bandello F, et al. Aflibercept in the treatment of diabetic macular edema: a review and consensus paper. Eur J Ophthalmol 2017;27:627-39.
Cite this article as: Liu Y, Cheng J, Gao Y, Qin L, Min X, Zhang M. Efficacy of switching therapy to aflibercept for patients with persistent diabetic macular edema: a systematic review and meta-analysis. Ann Transl Med 2020;8(6):382. doi: 10.21037/atm.2020.02.04 


\section{Supplementary}

A

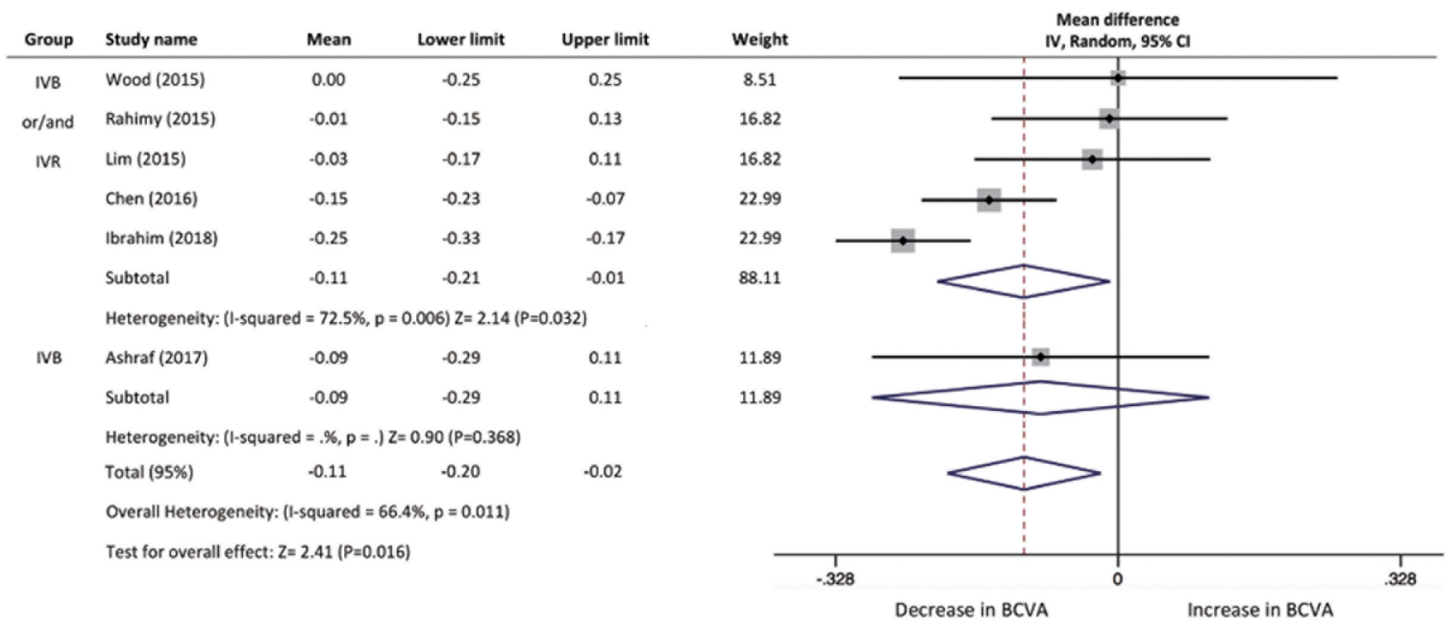

B

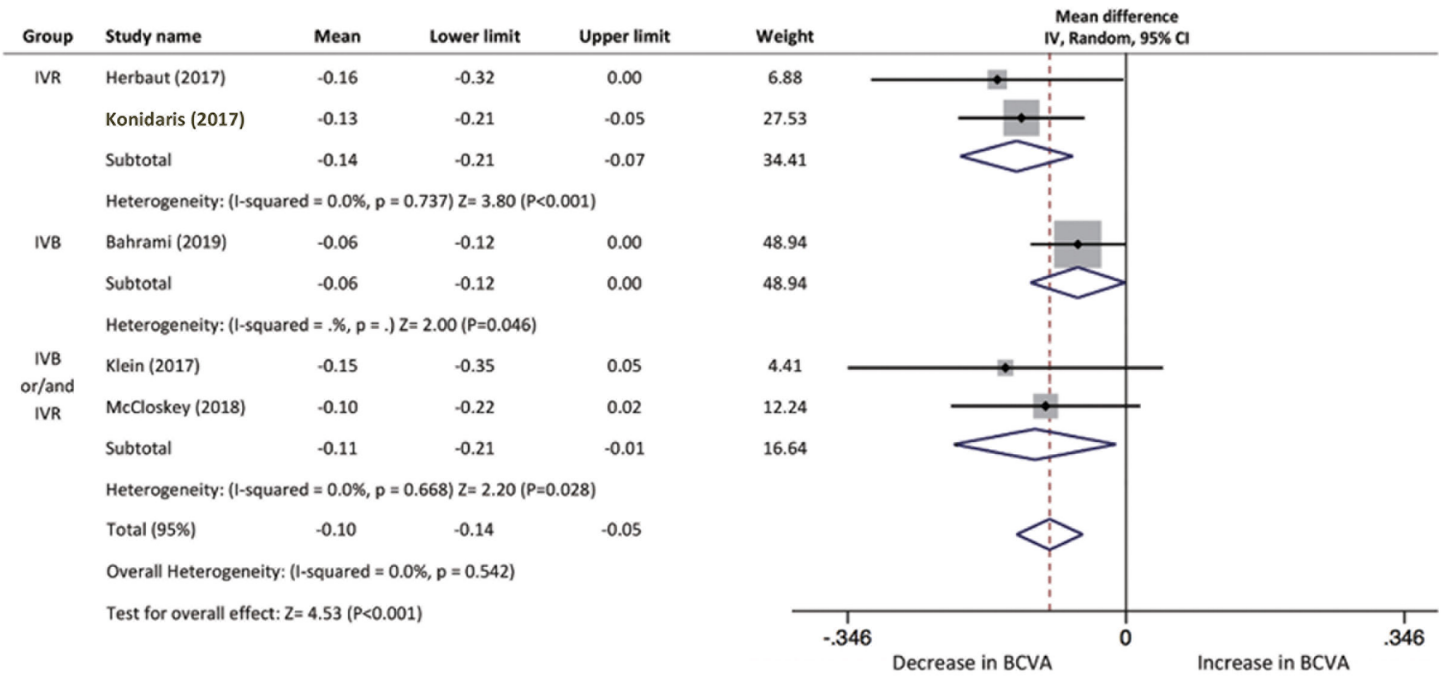

Figure S1 Forest plot showing outcomes of best-corrected visual acuity (BCVA, logMAR) in different subgroups (IVB, IVR, IVB and/or IVR) after the switch. (A) 1 month; (B) 6 months. 
A

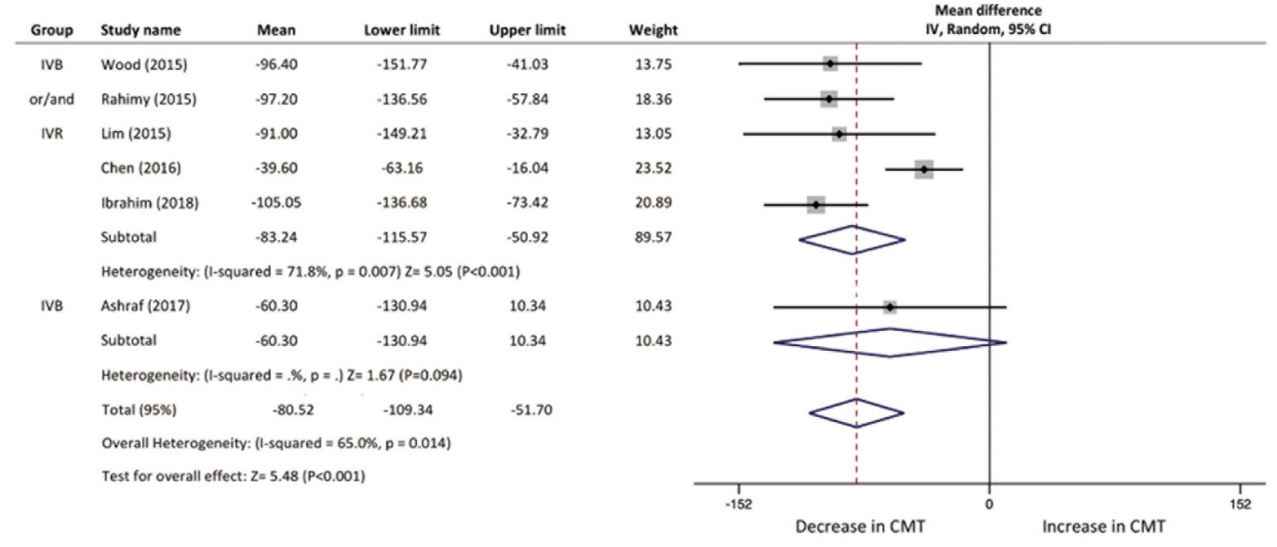

B

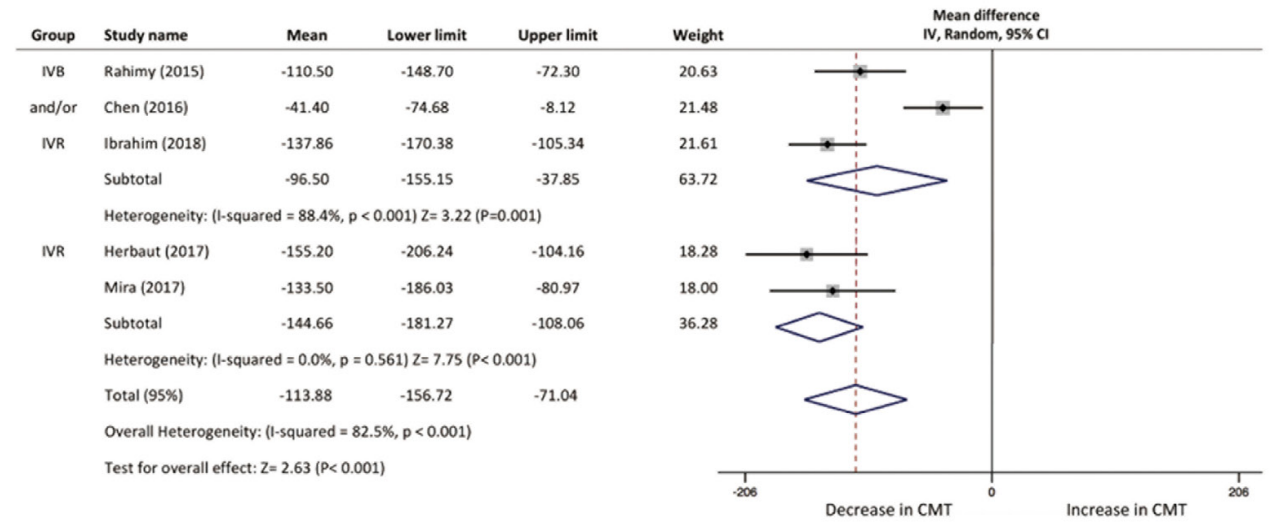

C

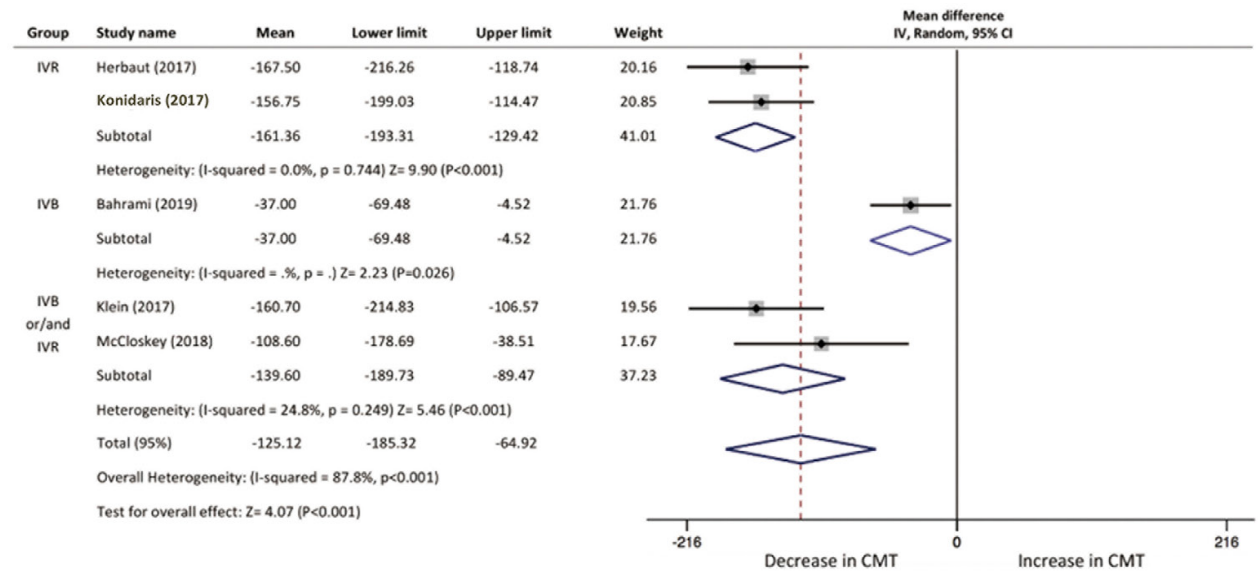

Figure S2 Forest plot showing outcomes of central macular thickness (CMT, $\mu \mathrm{m})$ in different subgroups (IVB, IVR, IVB and/or IVR) after the switch. (A) 1 month; (B) 3 months; (C) 6 months. 
Table S1 Study characteristics of the fourten trials in the meta-nalysis

\begin{tabular}{|c|c|c|c|c|}
\hline Authors & Year & Adverse & Definition of treatment resistance & Inclusion/exclusion criteria \\
\hline Herbaut et al. & 2017 & No serious adverse event following intravitreal injections & $\begin{array}{l}\text { Persistent DME defined by a loss of the foveal pit, and a CRT } \\
>300 \mu \mathrm{m} \text { on SD-OCT responsible for a loss of vision [pre- } \\
\text { switch visual acuity (VA)] }\end{array}$ & $\begin{array}{l}\text { Inclusion: Patients with type } 1 \text { or } 2 \text { diabetes, with persistent DME. Only patients who received at least the first } 3 \text { monthly affibercept injections were included in } \\
\text { the study. Exclusion: other ocular conditions impairing vision or complication of diabetic retinopathy, fewer than three IVR prior to the switch to affibercept, and } \\
\text { incomplete imaging or clinical data }\end{array}$ \\
\hline Bahrami et al. & 2019 & $\begin{array}{l}\text { Notable ocular adverse events included a rhegmatogenous } \\
\text { retinal detachment. There was no progression of cataract severity } \\
\text { or raised IOP in any of the study eyes, and no patients required } \\
\text { medical or surgical intervention for cataract or raised IOP }\end{array}$ & $\begin{array}{l}\text { Persistent central macular thickening identitied by OCT and/ } \\
\text { or a loss of } 10 \text { ETDRS letters in vision despite 4-weekly } \\
\text { intravitreal injections }\end{array}$ & $\begin{array}{l}\text { Inclusion: Patients aged } 18 \text { or older, with DME secondary to type } 1 \text { or type } 2 \text { diabetes mellitus, BCVA between } 34 \text { and } 85 \text { ETDRS Ietters, retinal thickness } \\
\text { greater than } 300 \text { m in the central } 1 \mathrm{~mm} \text { ETDRS field on SD-OCT and at least } 4 \text { previous IVB }(2.5 \mathrm{mg} / 0.1 \mathrm{mLL} \text { in the } 6 \text { months prior to baseline examination. } \\
\text { Exclusion: Intravitreal steroid therapy or vitrectomy surgery in the study eye within } 3 \text { months of baseline, cataract surgery or macular laser within } 2 \text { months of } \\
\text { baseline, pregnancy, and uncontrolled diabetes mellitus (HbA1c }>12 \% \text { ) }\end{array}$ \\
\hline McCloskey et al. & 2018 & $\begin{array}{l}\text { No significant systemic or ocular adverse events during our } \\
\text { study period }\end{array}$ & $\begin{array}{l}\text { No decline, partial resolution or increase in fluid on OCT } \\
\text { comparable with fundal examination and declining or no } \\
\text { improvement in VA }\end{array}$ & $\begin{array}{l}\text { Inclusion: DMO Patients received at least three previous consecutive IVR }(0.5 \mathrm{mg}) \text {, IVB }(1.25 \mathrm{mg}) \text { or both in the } 6 \text { months prior to conversion. Exclusion: Patients } \\
\text { received procedures affecting possible visual outcomes including phacoemulsification, YAG capsulotomy and corticosteroid treatment during the treatment } \\
\text { period }\end{array}$ \\
\hline Nixon et al. & 2018 & $\begin{array}{l}\text { No ocular or non-ocular adverse events were reported in the } \\
\text { patient population during the study }\end{array}$ & Persistent fluid on SD-OCT following at least 3 consecutive IVR & $\begin{array}{l}\text { Inclusion: Aged } 18 \text { or older; ability to complete study; more than } 3 \text { IVR over previous } 6 \text { months; persistent fluid on OCT, VA } 6 / 30 \text {. Exclusion: Intraocular pressure } \\
25 \mathrm{mmH} \text {; prior retinal surgery or significant subretinal scarring, cataracts, or vitreous hemorrhage; anti-VEGF treatment within prior } 30 \text { days; intravitreal steroid } \\
\text { treatment within prior } 6 \text { months; MI, TIA, or CVA within prior } 90 \text { days; current pregnancy or lactation. }\end{array}$ \\
\hline Wood et al. & 2015 & Treatment was well-tolerated with no adverse events & $\begin{array}{l}\text { Persistent intraretinal or subretinal fluid despite at least three } \\
\text { monthly IVR or IVB }\end{array}$ & $\begin{array}{l}\text { Inclusion: DME patients with persistent retinal fluid despite regular (every } 4 \text { to } 6 \text { weeks) IVR } 0.3 \mathrm{mg} \text { and/or IVB } 1.25 \mathrm{mg} \text { who were switched to aflibercept } 2 \mathrm{mg} \text {. } \\
\text { Exclusion: Patients with other vision-limiting conditions besides DME or other possible causes of macular edema. }\end{array}$ \\
\hline Rahimy et al. & 2016 & $\begin{array}{l}\text { No ocular adverse events; no systemic thromboembolic adverse } \\
\text { events }\end{array}$ & $\begin{array}{l}\text { Persistent DME with no reduction, incomplete resolution, } \\
\text { or an increase in central subfield thickening by SD-OCT, } \\
\text { necessitating additional anti-VEGF therapy at the time of } \\
\text { conversion }\end{array}$ & $\begin{array}{l}\text { Inclusion: Patients aged } 18 \text { years or older with diabetes mellitus (type } 1 \text { or type 2), macular edema and commensurate center-involving DME (CMT }>300 \text { um) } \\
\text { by SD-OCT imaging; persistent exudative fluid; eyes treated with at least } 4 \text { consecutive IVR/VB performed at thu exact same interval prior to conversion and } \\
\text { with at least } 2 \text { IVA afterward at that same interval. Exclusion: Any of the following treatments during the 6-month period prior to anti-VEGF conversion or after: } \\
\text { intravitreal or sub-Tenon injections of corticosteroids, et all; ;oncomitant ocular diseases aside from NDPR in the treated eye: AMD, CRVO/BRVO, choroidal } \\
\text { neovascularization, history of ocular trauma, or prior intraccular surgery }\end{array}$ \\
\hline Konidaris et al. & 2017 & N/A & N/A & N/A \\
\hline Mira et al. & 2017 & $\begin{array}{l}\text { No ocular or systemic thromboembolic adverse events were } \\
\text { registered }\end{array}$ & $\begin{array}{l}\text { Persistent or increasing sub- or intraretinal fluid on SD-OCT } \\
\text { after } 3 \text { or more consecutive monthly injections regardless of } \\
\text { vision }\end{array}$ & $\begin{array}{l}\text { Inclusion: Diabetic type } 2 \text { patients aged } 18 \text { years or older with DME unresponsive to anti-VEGF with a minimum of } 3 \text { injections } 4 \text { months before switch and } \\
3 \text { months of follow-up. Exclusion: Macular edema secondary to a cause other than diabetes, complications of diabetic retinopathy, myopia greater than -6 } \\
\text { diopters, ocular surgery } 6 \text { months prior to switch, presence of drüsens, and incomplete clinical data }\end{array}$ \\
\hline Klein et al. & 2017 & $\begin{array}{l}\text { No ocular adverse events. No systemic adverse events such as } \\
\text { thromboembolic phenomena. }\end{array}$ & $\begin{array}{l}\text { Persistent cystic change with } \leq 15 \% \text { decrease in CRT over } \\
\text { the } 6 \text { months prior to IAl switch despite having at least } 4 \text { total } \\
\text { treatments for DME, with at least } 3 \text { of these treatments being } \\
\text { intravitreal anti-VEGF injections (excluding IAI) }\end{array}$ & $\begin{array}{l}\text { Inclusion: Recalcitrant to current therapy; age } 18 \text { years or older; clear ocular media; baseline IOP of } 21 \mathrm{mmHg} \text { or less with or without pressure-lowering drops } \\
\text { in patients previously treated with corticosteroids; Snellen VA between 20/40 and 20/300. Exclusion: Previous IAl in the study eye and history of systemic anti- } \\
\text { VEGF use }\end{array}$ \\
\hline Limetal. & 2015 & N/A & N/A & $\begin{array}{l}\text { Inclusion: Refractory DME treated with IVR and/or IVB. Exclusion: Other visually significant ocular pathology and complications of diabetic retinopathy, loss to } \\
\text { follow-up, fewer than three IVR and/or IVB prior to conversion to affibercept, and incomplete imaging or clinical data }\end{array}$ \\
\hline Ashraf et al. & 2017 & N/A & N/A & $\begin{array}{l}\text { Inclusion: Patients with diabetes mellitus (type } 1 \text { or } 2 \text { ) aged over } 18 \text { with center-involved DME, nonresponse to bevacizumab and treatment duration of less than } \\
9 \text { months since the start of therapy. Exclusion: Vitreoretinal interface abnormality on SD-OCT that may contribute to macular edema or presence of any other } \\
\text { significant macular pathology or postsurgical macular edema, as well as previous treatment duration of greater than } 9 \text { months prior to switching }\end{array}$ \\
\hline Laiginhas et al. & 2018 & N/A & N/A & 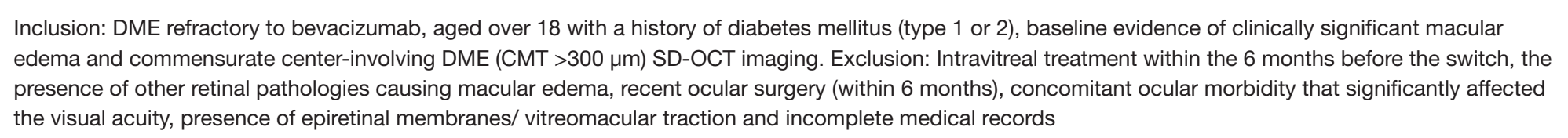 \\
\hline Ibrahim et al. & 2019 & $\begin{array}{l}\text { Only four cases of subconjunctival hemorrhage were reported, } \\
\text { with no other serious ocular and systemic adverse events }\end{array}$ & N/A & $\begin{array}{l}\text { Inclusion: Resistant DME defined as above. Exclusion: Unwillingness to participate; significant cataract or corneal opacity; DME associated with PDR; history } \\
\text { of laser treatment or steroid injection in the previous } 6 \text { months, co-existing retinal pathology; history of cataract surgery in the previous } 12 \text { months, associated } \\
\text { optic nerve disorders, glycosylated hemoglobin higher than } 8 \% \text { at the time of participation, ischemic heart disease, or previously complicated intravitreal } \\
\text { injection of anti-VEGF; fewer than } 3 \text { consecutive IVI }\end{array}$ \\
\hline Chen et al. & 2017 & $\begin{array}{l}\text { No systemic adverse events, such as thromboembolic events, } \\
\text { were noted }\end{array}$ & $\begin{array}{l}\text { A paradoxical increase in } \mathrm{CFT} \text { and gain in BCVA of less } \\
\text { than } 1 \text { line at } 1 \text { month after at least } 3 \text { months of continuous } \\
\text { treatment compared with before bevacizumab or ranibizumab } \\
\text { administration }\end{array}$ & $\begin{array}{l}\text { Inclusion: Aged over } 18 \text { with history of diabetes mellitus and clinically significant macular edema defined by the ETDRS and center-involving DME; DME } \\
\text { resistance to bevacizumab or ranibizumab. Exclusion: Patients with prior ocular trauma, vitreomacular adhesion or traction, epimacular membrane, tractional } \\
\text { retinal detachment, vitreous hemorrhage, other ocular disorders, prior intravitreal or sub-Tenon injections of corticosteroids or intravitreal corticosteroid } \\
\text { implants, or other previous intraocular surgeries }\end{array}$ \\
\hline
\end{tabular}

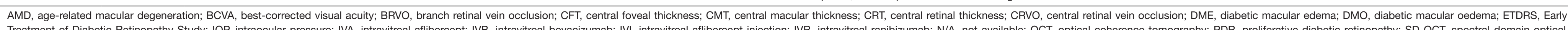

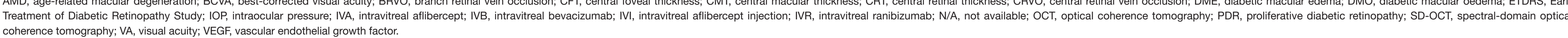

